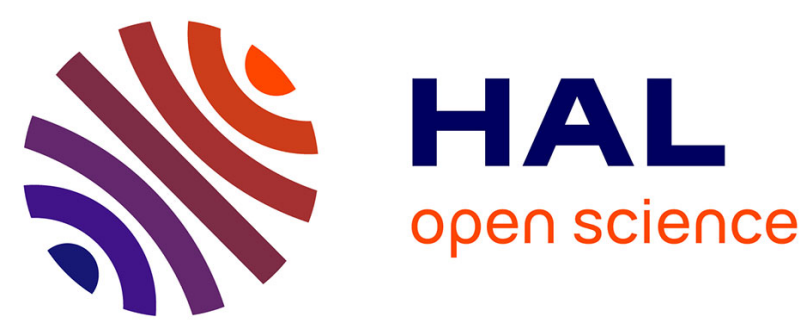

\title{
Evidence for a pleiotropic QTL on chromosome 5q13 influencing both time to asthma onset and asthma score in French EGEA families.
}

Emmanuelle Bouzigon, Ayse Ulgen, Marie-Hélène Dizier, Valérie Siroux, Mark Lathrop, Francine Kauffmann, Isabelle Pin, Florence Demenais

\section{To cite this version:}

Emmanuelle Bouzigon, Ayse Ulgen, Marie-Hélène Dizier, Valérie Siroux, Mark Lathrop, et al.. Evidence for a pleiotropic QTL on chromosome 5q13 influencing both time to asthma onset and asthma score in French EGEA families.. Human Genetics, 2007, 121 (6), pp.711-719. 10.1007/s00439-0070363-x . inserm-00139064

\section{HAL Id: inserm-00139064 https://www.hal.inserm.fr/inserm-00139064}

Submitted on 4 May 2007

HAL is a multi-disciplinary open access archive for the deposit and dissemination of scientific research documents, whether they are published or not. The documents may come from teaching and research institutions in France or abroad, or from public or private research centers.
L'archive ouverte pluridisciplinaire HAL, est destinée au dépôt et à la diffusion de documents scientifiques de niveau recherche, publiés ou non, émanant des établissements d'enseignement et de recherche français ou étrangers, des laboratoires publics ou privés. 


\section{HAL author manuscript}

Evidence for a pleiotropic QTL on chromosome $5 q 13$ influencing both time to asthma onset and asthma score in French EGEA families

Emmanuelle Bouzigon ${ }^{1,2}$, Ayse Ulgen ${ }^{1,2}$, Marie-Hélène Dizier ${ }^{3,4}$, Valérie Siroux ${ }^{5}$, Mark Lathrop ${ }^{6}$, Francine Kauffmann ${ }^{4,7}$, Isabelle Pin ${ }^{5}$, Florence Demenais ${ }^{1,2}$

${ }^{1}$ INSERM, U794, Evry, France; ${ }^{2}$ Université d'Evry, Evry, France; ${ }^{3}$ INSERM, U535, Villejuif, France; ${ }^{4}$ Univ. Paris-Sud, IFR69, Villejuif, France; ${ }^{5}$ INSERM, U823,

Grenoble, France; ${ }^{6}$ Centre National de Génotypage, Evry, France; ${ }^{7}$ INSERM, U780, Villejuif, France.

\section{Corresponding author:}

Emmanuelle Bouzigon,

INSERM U794,

Tour Evry 2, 523 Place des Terrasses de l'Agora,

91034 Evry - France

Tel: +33 160873820 ,

Fax: +33160873848

E-mail: bouzigon@evry.inserm.fr

Keywords: Asthma, bivariate, genetic linkage, pleiotropy, principal components 


\begin{abstract}
Although many genome screens have been conducted for asthma as a binary trait, there is limited information regarding the genetic factors underlying variation of asthma expression. Phenotypes related to variable disease expression include time to asthma onset and variation in clinical expression as measured by an asthma score built from EGEA data. A recent genome scan conducted for this score led to detection of a new region (18p11) not revealed by analysis of dichotomous asthma. Our goal was to characterize chromosomal regions harbouring genes underlying time to asthma onset and to search for pleiotropic QTL influencing both time to asthma onset and the asthma score. We conducted a genome-wide linkage screen for time to asthma onset, modelled by martingale residuals from Cox survival model, in EGEA families with at least two asthmatic sibs. This was followed by a bivariate linkage scan of these residuals and asthma score. Univariate linkage analysis was performed using the Maximum Likelihood Binomial method that we extended to bivariate analysis.

This screen revealed two regions potentially linked to time to asthma onset, $1 \mathrm{p} 31$ $(\mathrm{LOD}=1.70, \mathrm{p}=0.003)$ and $5 \mathrm{q} 13(\mathrm{LOD}=1.87, \mathrm{p}=0.002)$. Bivariate linkage analysis led to a substantial improvement of the linkage signal on $5 \mathrm{q} 13(\mathrm{p}=0.00007)$, providing evidence for a pleiotropic QTL influencing both variation of time to asthma onset and of clinical expression.

Use of quantitative phenotypes of variable disease expression and suitable statistical methodology can improve the power to detect new regions harbouring genes which may play an important role in onset and course of disease.
\end{abstract}




\section{INTRODUCTION}

Asthma is a complex disease with variable clinical expression and resulting from many genetic and environmental risk factors (Ober and Hoffjan 2006). Asthma is unlikely to be a single disease but rather a collection of different phenotypes which may represent different manifestations of a common underlying pathological process or may be separate disease entities, as recently reviewed by Wenzel (Wenzel 2006). These phenotypes can be characterized from various criteria including clinical and physiological features such as severity of clinical symptoms, type of asthma treatment, and age of onset of asthma.

It has been shown that use of quantitative scores based on symptoms of asthma rather than simple dichotomous definitions can improve the identification of risk factors (Pekkanen et al. 2005). We have recently conducted a genome-wide screen for a categorical asthma score, which was built from clinical symptoms and type of asthma treatment and represented the whole spectrum of disease expression (from unaffecteds to severely affecteds), in families from the Epidemiological Study on the Genetics and Environment of Asthma (EGEA). This scan led to detection of linkage of this asthma score to 18 p1 1 (Bouzigon et al. 2006), a new region that was not revealed by a previous screen for asthma using a classical dichotomous definition (Bouzigon et al. 2004).

Asthma age of onset is another interesting feature that may be worth considering to characterize the underlying determinants of this disease which displays different characteristics according to the lifetime period at which it occurs. Patients with early age at onset (i.e. before puberty) were reported to have more frequently a family history of asthma, allergy sensitisation and clinical response to triggers than patients with late-onset 
disease (Hsu et al. 2004; Miranda et al. 2004; Oryszczyn et al. 2006). Despite a potential longer duration of disease, subjects with early-onset asthma were shown to have marginally better lung function than those with late-onset disease. However, the severity of asthma in early childhood substantially determines the severity of the symptoms in later years (de Marco et al. 2006).

Despite the considerable efforts made over the past ten years to map the chromosomal location of genes that may be involved in the development of asthma (Bouzigon et al. 2005; Ober and Hoffjan 2006), none of the 16 genome scans conducted to date have examined the variability of asthma age-of-onset using survival analysis concepts. Such approach can take into account age at onset for individuals who developed the disease and age at time of examination for those who were free of disease upon examination but were still at risk for the disease. One interesting feature of published genome screens is that a given chromosomal region is often linked to various asthma-associated phenotypes across studies, suggesting that these phenotypes may share genetic determinants. Multivariate genetic linkage analyses of correlated phenotypes have been shown to improve power of detecting genes with small effects where these genes may be missed with univariate analyses (Allison et al. 1998; Marlow et al. 2003). However, the formal characterization of pleiotropic effects of genes underlying two or more asthma-related phenotypes has received little attention.

The goal of the present study was to characterize chromosomal regions that may harbour genes underlying time to asthma onset and to search for pleiotropic genetic determinants that may influence both variability in asthma age-of-onset and variation in clinical expression of asthma as measured by the asthma score. We first carried out a 
genome-wide linkage screen, in EGEA families with at least to asthmatic sibs, for time to asthma onset modelled by martingale residuals (MR) obtained from Cox proportional hazards model, using the Maximum Likelihood Binomial (MLB) linkage analysis method (Abel and Muller-Myhsok 1998; Alcais and Abel 1999). We then extended the MLB method to bivariate linkage analysis of MR and asthma score. 


\section{SUBJECTS AND METHODS}

\section{EGEA study}

The protocol of the EGEA data collection has been described elsewhere (Kauffmann et al. 2001; Kauffmann et al. 1997). Subjects answered a detailed questionnaire regarding respiratory symptoms and treatment based on international standardized questionnaires. Among the whole EGEA family sample ascertained through one asthmatic proband, 119 nuclear families including at least two asthmatic sibs were selected for the present study. Asthma was defined using the same criteria as in previous EGEA linkage scans (Bouzigon et al. 2004), associating report of asthma attacks or attacks of breathlessness with wheezing ever and either airway hyperresponsiveness or reversible obstruction or hospitalisation for asthma or asthma treatment.

\section{Time to asthma onset}

For individuals who developed asthma, information on asthma age at onset was obtained from adult asthmatics or parents of asthmatic children who answered to the following question: "How old were you when you had your first asthma attack?" or "How old was your child when he (or she) had his (her) first asthma attack?". For individuals who were free of disease upon examination, we considered age at examination; these individuals represented censored observations, as they were still at risk for disease. 


\section{Asthma score}

The asthma score, we analyzed previously (Bouzigon et al. 2006), was built to represent the whole spectrum of disease expression, encompassing both non-asthmatics and asthmatics. This score ranged from 0 to 4 : a score of zero was assigned to nonasthmatics and the scores of 1 to 4 represented various degrees of asthma severity. To briefly summarize, the four classes of asthma severity were defined in two steps by combining clinical items and level of treatment. In step 1, the sum of the following clinical items regarding the last 12 months was computed: frequency of asthma attacks (graded from 0 to 3); symptoms between asthma attacks (graded from 0 to 3 ); and hospitalisation for asthma (no(0)/yes(1)). This sum of clinical items was grouped into 4 classes: $0,1,2$ and $\geq 3$. In step 2, this 4-class variable built in step 1 was combined with the type of anti-asthmatic treatment in the past 12 months as reported in the EGEA questionnaire (no treatment, treatment without inhaled steroids, treatment with inhaled steroids) following the concept of combining treatment and symptoms according to the 2004 GINA guidelines (National Heart, Lung and Blood Institute 2002) and resulting into an asthma severity score taking the values $1,2,3$ or 4 .

\section{Genotyping}

Genotyping of 396 microsatellites was performed in EGEA families with at least two sibs with DNA (Bouzigon et al. 2004). These markers were distributed at an average marker density of 10 centimorgans $([\mathrm{cM}])$ and had an average heterozygosity of $75 \%$. After rigorous genotype quality control, the final sample included 110 families (508 
subjects) with at least two asthmatic sibs, comprising 218 genotyped parents ( $99 \%$ of all parents) and 288 genotyped sibs.

\section{Statistical analyses}

Time to asthma onset was analyzed using survival analysis methods. We considered the martingale residuals from Cox proportional hazards model, as defined by Barlow and Prentice (Barlow and Prentice 1988), using STATA 7.0. The observed times were failure times (age at disease onset) in asthmatics and censoring times (age at examination or death from a competing cause) in non-asthmatics. The martingale residual $r_{M i}$ for individual $\mathrm{i}$, is:

$$
r_{M i}=\delta_{\mathrm{i}}-\hat{\Lambda}_{0}\left(t_{i}\right) \exp \left(\beta z_{i}\right)
$$

where $\delta$ is a censoring indicator which is equal to one if the failure time is less than the censoring time (affected) or zero otherwise (unaffected), $\hat{\Lambda}_{0}\left(t_{i}\right)$ is the estimated cumulative baseline hazard function evaluated at age at asthma diagnosis (age at onset) if $i$ is asthmatic or at age at examination if $i$ is unaffected, and $\beta$ is the estimated regression coefficient associated with covariate $z$. The only covariate included in the model was sex.

Descriptive statistics of age at asthma onset, age at examination and martingale residuals (MR) were computed in asthmatics and non-asthmatics and by gender. The medians of MR across asthma score classes were compared using non-parametric Kruskal-Wallis Rank Test. The relationship between MR and asthma score was estimated by Spearman rank correlation. All computations were done using STATA 7.0. 
Linkage analysis of the martingale residuals was performed using the Maximum Likelihood Binomial method (Abel and Muller-Myhsok 1998; Alcais and Abel 1999), as implemented in MLB-GENEHUNTER (Abel and Muller-Myhsok 1998). As opposed to the Variance Components (VC) method, this method does not require the assumption of normality of the distribution of the quantitative phenotype (Alcais and Abel 1999) and is therefore well suited to the analysis of martingale residuals which usually display skewness and kurtosis. The principle of this approach is to introduce a latent (unobserved) binary variable $(\mathrm{Y}=\{0 ; 1\})$ which captures the linkage information between the observed quantitative phenotype and the marker. For each observed phenotypic value, the latent (unobserved) variable $\mathrm{Y}$ can take the value of 1 (being affected) with probability $P_{i}$ and the value of 0 (being unaffected) with probability $1-P_{i}$. The idea is that the probability for the latent variable $\mathrm{Y}$ to be equal to 1 increases as the observed phenotypic values increase. Linkage is then investigated for all possible sets of $\mathrm{Y}$ values within sibships weighted by their probabilities. The link function between the observed phenotype and latent variable was based on the empirical trait distribution. When analysing MR, we divided the trait values into 10 consecutive subclasses according to its decile distribution. If $d\left(z_{i}\right)$ is the decile corresponding to the value of the phenotype $z_{\mathrm{i}}$, $d\left(z_{i}\right)=\{1 ; 2 ; . \quad . \quad ; 10\}$, the corresponding probabilities were $P\left(y_{i}=1 \mid z_{i}\right)=0.1\left[d\left(z_{i}\right)\right]-0.05$, and $P\left(y_{i}=0 \mid z_{i}\right)=1-P\left(y_{i}=1 \mid z_{i}\right)$. Siblings belonging to classes 1-4 had negative martingale residuals while sibs in classes 5-10 had positive residuals. Given a set of values of the latent variable $\mathrm{Y}$ in a sibship, the distribution of marker alleles from heterozygous parents among siblings is written by use of a binomial distribution which depends on one parameter, $\alpha$ (probability that sibs with $\mathrm{Y}=1$ receive 
one of the two marker alleles with disease allele from his/her heterozygous parent, $1-\alpha$ being the corresponding probability among sibs with $\mathrm{Y}=0$ ). Test for linkage (null hypothesis of no linkage $(\alpha=0.5)$ vs the alternative hypothesis of linkage $(\alpha>0.5))$ is performed using a likelihood-ratio $(\mathrm{LR})$ test, $\mathrm{LR}=2 \mathrm{Ln}[\mathrm{L}(\alpha) / \mathrm{L}(\alpha=0.5)]$ with $\mathrm{LR}$ being asymptotically distributed as a mixture of $0.5 \chi_{0}^{2}$ and $0.5 \chi^{2}$. This statistic divided by $2 \ln 10$ is a LOD score.

We extended the MLB method to bivariate linkage analysis of the martingale residuals and asthma score, following an approach proposed by Mangin et al. (Mangin et al. 1998). These authors showed that the likelihood-ratio test used to test for the presence of a pleiotropic QTL in multivariate variance components (VC) analysis is asymptotically equivalent to the sum of likelihood-ratio tests of univariate $\mathrm{VC}$ analyses applied to the principal components of the traits. In a first step, a principal components (PC) analysis was applied to the two phenotypes, MR and asthma score, to obtain two uncorrelated principal components, using STATA 7.0. These components were then subjected to independent univariate linkage analyses based on the MLB method. In the MLB analysis, we used the decile distribution for each PC, as described above. In a second step a combined test statistic, T, was constructed by summing the univariate MLB likelihoodratio (LR) test statistics obtained for each of the two PCs: $\mathrm{T}=\sum_{i=1}^{2} L R$, where the distribution of each $\mathrm{LR}_{\mathrm{i}}$ test, under the null hypothesis of no linkage, is a mixture of $1 / 2$ $\chi_{0}^{2}+1 / 2 \chi_{1}^{2}$. Since the two principal components are independent, the asymptotic distribution of the combined test statistic $\mathrm{T}$ is a mixture of $1 / 4 \chi_{0}^{2}+1 / 2 \chi_{1}^{2}+1 / 4 \chi_{2}^{2}$. 


\section{RESULTS}

\section{Descriptive statistics of the phenotypes}

As seen in Table 1, the 288 genotyped siblings included $82 \%$ of asthmatics. The median (25-75 quartiles) of age at examination of all sibs was 12 years (10-18): it was 12 years (10-18) in asthmatics and 12 years (8-18) in non-asthmatics. In asthmatics, the median (25-75 quartiles) of age at asthma onset was 4 years (2-8) and the median of duration of disease between age at onset and age at examination was 8 years with $25-75$

Table 1 quartiles being $(5-11)$.

The proportion of males did not differ between asthmatic and non-asthmatic sibs $(59.5 \%$ and $53 \%$ respectively, $\mathrm{p}=0.40)$. However, while the median of age at examination in non-asthmatics did not differ between males and females (15.1 years of age versus 12.2 years of age, $\mathrm{p}=0.39$ ), the median of age at asthma onset in asthmatics was higher in females than in males (6 years of age versus 4 years of age, $p=0.01$ ). Thus, sex was included as a covariate in the Cox proportional hazards model from which martingale residuals were obtained. The distribution of these martingale residuals showed a median equal to 0.23 , the $25-75$ quartiles being $(-0.47-0.65)$. This phenotype displayed significant skewness $\left(p<10^{-4}\right)$ and kurtosis $(p=0.01)$.

Regarding the asthma score, $18 \%$ of sibs had a score of zero, $38 \%$ a score of 1 , $19 \%$ a score of $2,12 \%$ of score 3 and $12 \%$ a score of 4 (Table 1 ). Figure 1 shows the

Figure 1 distribution of martingale residuals according to the five classes of the asthma score. As expected, the median of MR was much lower in non-asthmatics (median = -1.16) than in asthmatics (median $\geq 0.40$ ). In asthmatics, the medians of MR did not differ among the four classes of the asthma score, these medians being 0.40 for scores of 1,2 and 4 and 
0.53 for a score of $3(p=0.64)$. However, the range of the $25-75 \%$ quartiles increased as the asthma score increased, this range being $(0.15-0.70)$ for a score equal to 1 and $(-0.26-$ 0.74) for a score equal to 4. Interestingly, the duration of disease had a similar distribution across the four asthma score classes $(p=0.82)$, with medians of 8 for scores of 1 and 4 and medians of 7 for scores of 2 and 3. The Spearman rank correlation between the martingales residuals and the asthma score was $0.41\left(\mathrm{p} \leq 10^{-4}\right)$.

\section{Genome-wide linkage screen}

The genome-wide linkage results for the univariate analysis of martingale residuals and bivariate analysis of MR and asthma score are presented in Figure 2. The regions detected at a p-value $\leq 0.005$ are shown in Table 2 . For purpose of comparing the results of bivariate and univariate analyses, the results previously obtained from univariate linkage analysis of the asthma score are also shown in Table 2.

There was suggestive evidence for linkage of martingale residuals to $1 \mathrm{p} 31$

Table 2 $(\mathrm{LOD}=1.70$ at $\mathrm{D} 1 \mathrm{~S} 2797, \mathrm{p}=0.003)$ and $5 \mathrm{q} 13(\mathrm{LOD}=1.87$ at $\mathrm{D} 5 \mathrm{~S} 424, \mathrm{p}=0.002)$. An additional linkage signal was observed in the $14 \mathrm{q} 13$ region $(\mathrm{LOD}=1.21$ at $\mathrm{D} 14 \mathrm{~S} 70, \mathrm{p}=$ 0.009). As seen from table 2 , the $5 \mathrm{q} 13$ and $14 \mathrm{q} 13$ regions included also linkage signals for the asthma score $(\mathrm{LOD}=1.22$ at $14 \mathrm{cM}$ telomeric from $\mathrm{D} 5 \mathrm{~S} 424, \mathrm{p}=0.009$ and $\mathrm{LOD}=$ 1.20 at D14S70, $\mathrm{p}=0.009$ ) while the $18 \mathrm{p} 11$ region that led to the highest evidence for linkage to this score $(L O D=2.40, p=0.0004)$ did not show any linkage signal to $M R$.

Prior to the bivariate genome-wide linkage analysis of the martingale residuals and asthma score, principal component analysis was applied to these two phenotypes and showed that the first and second principal components contributed respectively to $71 \%$ 
and $29 \%$ of the overall phenotypic variance. For the first component, the coefficients for MR and asthma score were each equal to 0.71 while, for the second component, the coefficients were 0.71 for MR and -0.71 for asthma score.

The bivariate linkage analysis of martingale residuals and asthma score led to a substantial improvement of the linkage signal on $5 \mathrm{q} 13$ (combined test statistic $\mathrm{T}$ being equal to $16.9, \mathrm{p}=0.00007$ ) at the same marker position (D5S424) found linked to MR by

Figure 3 univariate analysis (Figure 3 and Table 2). This result provides significant evidence for a pleitotropic QTL influencing both variability in time to asthma onset and variation in asthma clinical expression score in this region. There was also indication for potential pleiotropic effect of $14 q 13$ region on these two phenotypes $(p=0.006)$, although the increase in evidence for linkage as compared to the univariate linkage analyses of each phenotype was relatively small (the p-values associated with the univariate linkage signals being each equal to 0.009 ). Alternatively, there was no evidence for shared determinants by MR and asthma score on either $1 \mathrm{p} 31$ potentially linked to time to asthma onset or $18 \mathrm{p} 11$ found linked to the asthma score. 


\section{DISCUSSION}

Currently, there is a debate on the disease phenotypes that need to be considered to progress in the understanding of the mechanisms underlying as thma (Anonymous 2006). Up to now, genetic studies have used dichotomous phenotypes, either for the disease status itself (asthma/non asthma) or for subtypes of asthma (eg asthma with early onset, severe asthma...). The present genome-wide scan is the first one that has examined time to asthma onset. It is also the first bivariate genome-wide linkage screen ever conducted for asthma phenotypes and which examined two phenotypes related to variability of disease expression, time to asthma onset and a score measuring variation in clinical expression. The screen for time to asthma onset revealed two potential linkage regions on $1 \mathrm{p} 31$ and $5 \mathrm{q} 13$. The bivariate linkage scan led to significant evidence for a pleiotropic QTL on 5q13 influencing both the variation in time to asthma onset and the asthma score.

Linkage analysis was based on the MLB method rather than on the more widely used VC method since it does not require normality assumption of the trait distribution. Simulations have shown that the MLB approach does not lead to an increase of type I error even in presence of strong departure from normality (Alcais and Abel 1999). This approach was therefore particularly appropriate for martingale residuals which displayed significant skewness and kurtosis. Moreover, it was the method used for the analysis of the categorical asthma score (Bouzigon et al. 2006). To our knowledge, the formal characterization of pleiotropic effects of genes underlying asthma-related phenotypes has received little attention whereas multivariate linkage analyses have been performed for some time for other complex diseases (Kullo et al. 2005; Marlow et al. 2003; Williams et 
al. 1999). To carry out bivariate analysis of MR and asthma score, we extended the approach proposed by Mangin et al. (Mangin et al. 1998) for multivariate variance components analysis to the MLB method. The principle of replacing the likelihood-ratio test statistic of the multivariate linkage analys is by the sum of test statistics obtained from univariate linkage analyses of principal components of correlated phenotypes has been also used in the context of Haseman-Elston (H-E) sib-pair method for quantitative traits (Elston et al. 2000). This PC-based H-E multivariate test was shown to have identical and even higher power than a more complex multivariate H-E test (Gorlova et al. 2002). Although principal components are linear functions of the original phenotypes, simulations have shown that linkage analysis of standard principal components can detect accurately the genetic model underlying complex quantitative phenotypes (Moser et al. 2001). Moreover, this PC-based approach can be easily extended to the analysis of multiple traits without increasing the number of parameters to be estimated which raises major numerical problems when using the full multivariate approach.

Among the two linkage regions that were detected for time to asthma onset, $1 \mathrm{p} 31$ was previously revealed by a linkage screen for dichotomous asthma in the same EGEA families $(p=0.005)$ (Bouzigon et al. 2004). Further analysis showed that the $1 \mathrm{p} 31$ region was likely to contain a gene specific of the co-morbidity defined by the presence of both asthma and allergic rhinitis (Dizier et al. 2007). Interestingly, the frequency of allergic sensitisation is known to differ in early-onset and late-onset asthmatic patients, which may partly account for the linkage signal detected here for asthma age at onset. The $5 \mathrm{q} 13$ region potentially linked to time to onset for asthma was also harbouring a linkage signal 
for the asthma score, although smaller and $14 \mathrm{cM}$ apart from the former signal. Bivariate analysis of these phenotypes provided strong evidence for the presence of a pleiotropic QTL on $5 q 13$ influencing time to asthma onset and asthma score. Computation of the ratio of each PC-likelihood-ratio test statistic to the combined test statistic showed a higher contribution from $\mathrm{PC}_{2}(62 \%)$ than $\mathrm{PC}_{1}(38 \%)$. The first principal component appeared to represent the whole variation of both the asthma score and time to onset, the lowest $\mathrm{PC}_{1}$ values being observed in non-asthmatics with oldest age at examination (43 years of age) and the highest $\mathrm{PC}_{1}$ values being observed in asthmatics with the most severe form of disease and youngest age at onset $(<1$ year of age). For the second principal component, the lowest values were observed in most severely affected asthmatics with oldest age at onset (30 years of age) while the highest values were obtained in asthmatics with the mildest form of disease and youngest age at onset $(<1$ year of age). Note this $5 \mathrm{q} 13$ region was not detected by our previous screen of dichotomous asthma and seven asthma-associated phenotypes involved in atopy, inflammation and lung function (Bouzigon et al. 2004). This demonstrates that together considering more refined phenotypes representing variation in disease expression and use of multivariate analysis can increase power to detect new asthma genes. Alternatively, the $14 \mathrm{q} 13$ region included potential linkage signals to both time to asthma onset and asthma score at the same marker position but pleiotropic effect of this region was not highly supported, although this latter result would deserve to be confirmed by further genetic studies. Finally, the $18 \mathrm{p} 11$ region detected for the asthma score did not appear to influence variation in age at asthma onset. Previous investigation of heterogeneity of linkage to dichotomous asthma according to age at onset in the same EGEA sample 
indicated the presence of a genetic factor modifying asthma age at onset in the 7q21 region (Dizier et al. 2001), a region not detected by the present screen. However, this analysis was part of a first screen using a less dense set of markers (254 microsatellites) than the present one (396 microsatellites) and was based on a different statistical methodology that required stratifying affected sib-pairs using an a priori cut-off point, which was chosen to be the median of age-at-onset distribution ( 4 years of age). This $7 q 21$ signal corresponded to a genetic factor underlying asthma with a different effect according to age at onset (before or after 4 years of age) while the analysis conducted here allowed to reveal genetic factors influencing the whole variation in time to asthma onset in both asthmatics and non-asthmatics. Altogether, these results underline the complexity of the mechanism involved and the interest of combining multiple approaches to unravel the genetic determinants.

As in most genome-wide scans conducted for asthma, our univariate linkage signals did not reach the stringent genome-wide significance level $\left(\mathrm{p} \leq 2.10^{-5}\right)$ proposed by Lander and Kruglyack (Lander and Kruglyack 1995). However, this criterion applied to very dense maps of markers and, if the map is less dense, as it is the case here, it becomes conservative. To our knowledge, genome-wide significance thresholds for bivariate linkage analysis have not been derived. Although bivariate and univariate linkage test statistics cannot be directly compared, we computed the 1-df LOD score $\left(\operatorname{LOD}_{[1]}\right)$ required to give the same $\mathrm{p}$ value as is given by the true bivariate test statistic (Almasy et al. 1997). On chromosome $5 q 13$, the $\operatorname{LOD}_{[1]}$ was $3.15(p=0.00007)$, which could be considered as significant (Morton 1998). Nevertheless, it has been often advocated that 
replication of linkage results across studies are more important than a single high linkage peak and can provide support for the actual involvement of linkage regions. We have carried out an exhaustive compilation of linkage results from published genome scans performed to date in 16 different populations (without counting the EGEA study). We considered all previously reported linkage peaks with $\mathrm{p} \leq 0.01$, located at $20 \mathrm{cM}$ on either side of the three linkage signals revealed by the present screen. The $5 \mathrm{q} 13$ region was reported linked to dichotomous asthma in the Hutterites (an isolated population with European ancestry) and to a lung function phenotype $\left(\mathrm{FEV}_{1}\right)$ in Australian twins (Ferreira et al. 2005; Ober et al. 2000). Interestingly, a linkage signal located at $30 \mathrm{cM}$ of our peak was also detected in German families for an early asthma onset phenotype (Altmuller et al. 2005). This study examined subtypes of asthma which were analyzed as dichotomous phenotypes, early-onset asthma sib-pairs including one asthmatic sib with asthma symptoms occurring before the age of two years and the other sib having asthma onset before the age of four years. However, a genome screen conducted for variation in wheezing age of onset among asthmatics in an initial smaller sample of those German families (as part of an international Genetic Analysis Workshop) did not identify the 5q13 region but reported evidence for linkage to 6q24-25 (Alcais et al. 2001). Several genome screens have reported linkage signals to the $1 \mathrm{p} 31$ region for asthma and a few allergic phenotypes (IgE, atopy and atopic dermatitis) (Altmuller et al. 2005; Blumenthal et al. 2004; Bradley et al. 2002; Haagerup et al. 2002; Koppelman et al. 2002; Mathias et al. 2001; Xu et al. 2001). The 14q13 region was reported linked to asthma, atopy and lung function by three genome-wide screens (CSGA 1997; Blumenthal et al. 2004; Postma et al. 2005). 
The QTL detected on $5 \mathrm{q} 13$ is more likely to play a role in childhood asthma and possibly at a young age since $75 \%$ of the siblings investigated by the present study were less than 18 years old and $75 \%$ of asthmatics had an age of onset of asthma less than or equal to 8 years of age. In an attempt to identify potential candidate genes in the $5 \mathrm{q} 13$ region, we found a potential candidate gene, the corticotropin-releasing hormone-binding protein gene (CRHBP). This gene encodes a protein that inactivates the corticotropinreleasing hormone $(\mathrm{CRH})$ activity. This hormone has a central anti-inflammatory action by stimulating the hypothalamic-pituitary-adrenal axis and endogenous glucocorticoid production. In knock-out mice, $\mathrm{CRH}$ was shown to enhance allergen-induced airway inflammation and lung dysfunction (Silverman et al. 2004). Further investigation of this gene as possibly influencing asthma expression and age of onset is therefore warranted.

In conclusion, the present study shows that both use of quantitative phenotypes of varying disease expression, time to asthma onset and asthma score, and suitable statistical methodology can improve power to detect new regions harbouring genes that may play an important role in onset and course of disease. 


\section{ACKNOWLEDGMENTS}

\section{EGEA cooperative group:}

Coordination: F Kauffmann; F Demenais (genetics); I Pin (clinical aspects).

Respiratory epidemiology: Inserm U 578, Grenoble: V Siroux; Inserm U 700, Paris M Korobaeff (Egea1), F Neukirch (Egea1); Inserm U 707, Paris: I Annesi-Maesano; Inserm U 780, Villejuif: F Kauffmann, N Le Moual, R Nadif, MP Oryszczyn.

Genetics: Inserm U 393, Paris: J Feingold; Inserm U 535, Villejuif: MH Dizier; Inserm U 794, Evry: E Bouzigon, F Demenais; CNG, Evry: I Gut, M Lathrop.

Clinical centers: Grenoble: I Pin, C Pison; Lyon: D Ecochard (Egea1), F Gormand, Y Pacheco; Marseille: D Charpin (Egea1), D Vervloet; Montpellier: J Bousquet; Paris Cochin: A Lockhart (Egea1), R Matran (now in Lille); Paris Necker: E Paty, P Scheinmann; Paris-Trousseau: A Grimfeld, J Just.

Data and quality management: Inserm ex-U155 (Egea1): J Hochez; Inserm U 780, Villejuif: N Le Moual, C Ravault; Inserm U 794: N Chateigner; Grenoble: J Ferran

This work was partly supported by EU Framework programme for research, contract $\mathrm{n}^{\circ}$ FOOD-CT-2004-506378, the GA2LEN project, Global Allergy and Asthma European Network. 


\section{REFERENCES}

Abel L, Muller-Myhsok B (1998) Robustness and power of the maximum-likelihoodbinomial and maximum-likelihood-score methods, in multipoint linkage analysis of affected-sibship data. Am J Hum Genet 63: 638-47

Alcais A, Abel L (1999) Maximum-Likelihood-Binomial method for genetic model-free linkage analysis of quantitative traits in sibships. Genet Epidemiol 17: 102-17

Alcais A, Plancoulaine S, Abel L (2001) An autosome-wide search for loci underlying wheezing age of onset in German asthmatic children identifies a new region of interest on 6q24-q25. Genet Epidemiol 21 Supp1 1: S168-73

Allison DB, Thiel B, St Jean P, Elston RC, Infante MC, Schork NJ (1998) Multiple phenotype modeling in gene-mapping studies of quantitative traits: power advantages. Am J Hum Genet 63: 1190-201

Almasy L, Dyer TD, Blangero J (1997) Bivariate quantitative trait linkage analysis: Pleiotropy versus co-incident linkages. Genet Epidemiol 14: 953-8

Altmuller J, Seidel C, Lee YA, Loesgen S, Bulle D, Friedrichs F, Jellouschek H, Kelber J, Keller A, Schuster A, Silbermann M, Wahlen W, Wolff P, Schlenvoigt G, Ruschendorf F, Nurnberg P, Wjst M (2005) Phenotypic and genetic heterogeneity in a genome-wide linkage study of asthma families. BMC Pulm Med 5: 1

Anonymous (2006) A plea to abandon asthma as a disease concept. Lancet 368: 705

Barlow WE, Prentice RL (1988) Residuals for relative risk regression. Biometrika 75: 6574

Blumenthal MN, Langefeld CD, Beaty TH, Bleecker ER, Ober C, Lester L, Lange E, Barnes KC, Wolf R, King RA, Solway J, Oetting W, Meyers DA, Rich SS (2004) 
A genome-wide search for allergic response (atopy) genes in three ethnic groups: Collaborative Study on the Genetics of Asthma. Hum Genet 114: 157-64

Bouzigon E, Demenais F, Kauffmann F (2005) [Genetics of asthma and atopy: how many genes?]. Bull Acad Natl Med 189: 1435-48

Bouzigon E, Dizier MH, Krahenbuhl C, Lemainque A, Annesi-Maesano I, Betard C, Bousquet J, Charpin D, Gormand F, Guilloud-Bataille M, Just J, Le Moual N, Maccario J, Matran R, Neukirch F, Oryszczyn MP, Paty E, Pin I, RosenbergBourgin M, Vervloet D, Kauffmann F, Lathrop M, Demenais F (2004) Clustering patterns of LOD scores for asthma-related phenotypes revealed by a genome-wide screen in 295 French EGEA families. Hum Mol Genet 13: 3103-13

Bouzigon E, Siroux V, Dizier MH, Lemainque A, Pison C, Lathrop M, Kauffmann F, Pin I, Demenais F (2006) Scores of asthma and asthma severity reveal new regions of linkage in EGEA families. submitted Eur Respir J

Bradley M, Soderhall C, Luthman H, Wahlgren CF, Kockum I, Nordenskjold M (2002) Susceptibility loci for atopic dermatitis on chromosomes $3,13,15,17$ and 18 in a Swedish population. Hum Mol Genet 11: 1539-48

CSGA (1997) A genome-wide search for asthma susceptibility loci in ethnically diverse populations. The Collaborative Study on the Genetics of Asthma (CSGA). Nat Genet 15: 389-92

de Marco R, Marcon A, Jarvis D, Accordini S, Almar E, Bugiani M, Carolei A, Cazzoletti L, Corsico A, Gislason D, Gulsvik A, Jogi R, Marinoni A, MartinezMoratalla J, Pin I, Janson C (2006) Prognostic factors of asthma severity: a 9-year international prospective cohort study. J Allergy Clin Immunol 117: 1249-56 
Dizier MH, Besse-Schmittler C, Guilloud-Bataille M, Selinger-Leneman H, Kauffmann F, Clerget-Darpoux F, Demenais F (2001) Indication of linkage and genetic heterogeneity of asthma according to age at onset on chromosome $7 \mathrm{q}$ in 107 French EGEA families. Eur J Hum Genet 9: 867-72

Dizier MH, Bouzigon E, Guilloud-Bataille M, Genin E, Oryszczyn MP, Annesi-Maesano I, Demenais F (2007) Evidence for a locus in the 1p31 region specifically linked to the co-morbidity of asthma and allergic rhinitis in the EGEA study. Hum Hered 63: $162-7$

Elston RC, Buxbaum S, Jacobs KB, Olson JM (2000) Haseman and Elston revisited. Genet Epidemiol 19: 1-17

Ferreira MA, O'Gorman L, Le Souef P, Burton PR, Toelle BG, Robertson CF, Visscher PM, Martin NG, Duffy DL (2005) Robust estimation of experimentwise P values applied to a genome scan of multiple asthma traits identifies a new region of significant linkage on chromosome 20q13. Am J Hum Genet 77: 1075-85

Gorlova OY, Amos CI, Zhu DK, Wang W, Turner S, Boerwinkle E (2002) Power of a simplified multivariate test for genetic linkage. Ann Hum Genet 66: 407-17

Haagerup A, Bjerke T, Schiotz PO, Binderup HG, Dahl R, Kruse TA (2002) Asthma and atopy - a total genome scan for susceptibility genes. Allergy 57: 680-6

Hsu JY, King SL, Kuo BI, Chiang CD (2004) Age of onset and the characteristics of asthma. Respirology 9: 369-72

Kauffmann F, Dizier MH, Annesi-Maesano I, Bousquet J, Charpin D, Demenais F, Ecochard D, Feingold J, Gormand F, Grimfeld A, Lathrop M, Matran R, Neukirch F, Paty E, Pison C, Scheinmann P, Vervloet D, Lockhart A (2001) Étude 
épidémiologique des facteurs génétiques et environnementaux de l'asthme, l'hyperréactivité bronchique et l'atopie (EGEA). Protocole et biais de sélection potentiels. Rev Epidemiol Sante Publique 49: 343-56

Kauffmann F, Dizier MH, Pin I, Paty E, Gormand F, Vervloet D, Bousquet J, Neukirch F, Annesi I, Oryszczyn MP, Lathrop M, Demenais F, Lockhart A, Feingold J (1997) Epidemiological study of the genetics and environment of asthma, bronchial hyperresponsiveness, and atopy: phenotype issues. Am J Respir Crit Care Med 156: $\mathrm{S} 123-9$

Koppelman GH, Stine OC, Xu J, Howard TD, Zheng SL, Kauffman HF, Bleecker ER, Meyers DA, Postma DS (2002) Genome-wide search for atopy susceptibility genes in Dutch families with asthma. J Allergy Clin Immunol 109: 498-506

Kullo IJ, de Andrade M, Boerwinkle E, McConnell JP, Kardia SL, Turner ST (2005) Pleiotropic genetic effects contribute to the correlation between HDL cholesterol, triglycerides, and LDL particle size in hypertensive sibships. Am J Hypertens 18: 99-103

Lander E, Kruglyak L (1995) Genetic dissection of complex traits: guidelines for interpreting and reporting linkage results. Nat Genet 11: 241-247.

Mangin B, Thoquet P, Grimsley N (1998) Pleiotropic QTL analysis. Biometrics 54: 8899

Marlow AJ, Fisher SE, Francks C, MacPhie IL, Cherny SS, Richardson AJ, Talcott JB, Stein JF, Monaco AP, Cardon LR (2003) Use of multivariate linkage analysis for dissection of a complex cognitive trait. Am J Hum Genet 72: 561-70 
Mathias RA, Freidhoff LR, Blumenthal MN, Meyers DA, Lester L, King R, Xu JF, Solway J, Barnes KC, Pierce J, Stine OC, Togias A, Oetting W, Marshik PL, Hetmanski JB, Huang SK, Ehrlich E, Dunston GM, Malveaux F, Banks-Schlegel S, Cox NJ, Bleecker E, Ober C, Beaty TH, Rich SS (2001) Genome-wide linkage analyses of total serum $\operatorname{IgE}$ using variance components analysis in asthmatic families. Genet Epidemiol 20: 340-55

Miranda C, Busacker A, Balzar S, Trudeau J, Wenzel SE (2004) Distinguishing severe asthma phenotypes: role of age at onset and eosinophilic inflammation. J Allergy Clin Immunol 113: 101-8

Morton NE (1998) Significance levels in complex inheritance. Am J Hum Genet 62: 6907

Moser KL, Jedrey CM, Conti D, Schick JH, Gray-McGuire C, Nath SK, Daley D, Olson JM (2001) Comparison of three methods for obtaining principal components from family data in genetic analysis of complex disease. Genet Epidemiol 21 Suppl 1: S726-31

National Heart, Lung, and Blood Institute (2002) Global strategy for asthma management and prevention. Bethesda, MD: National Institutes of Health NIH Publication No. 02-95-3659. Updated 2004 from the 2003 document.

Ober C, Hoffjan S (2006) Asthma genetics 2006: the long and winding road to gene discovery. Genes Immun 7: 95-100

Ober C, Tsalenko A, Parry R, Cox NJ (2000) A second-generation genomewide screen for asthma-susceptibility alleles in a founder population. Am J Hum Genet 67: $1154-62$ 
Oryszczyn MP, Bouzigon E, Maccario J, Siroux V, Nadif R, Wright A, Kauffmann F (2006) Interrelationships of quantitative asthma-related phenotypes in the EGEA study. J Allergy Clin Immunol in press

Pekkanen J, Sunyer J, Anto JM, Burney P (2005) Operational definitions of asthma in studies on its aetiology. Eur Respir J 26: 28-35

Postma DS, Meyers DA, Jongepier H, Howard TD, Koppelman GH, Bleecker ER (2005) Genomewide screen for pulmonary function in 200 families ascertained for asthma. Am J Respir Crit Care Med 172: 446-52

Silverman ES, Breault DT, Vallone J, Subramanian S, Yilmaz AD, Mathew S, Subramaniam V, Tantisira K, Pacak K, Weiss ST, Majzoub JA (2004) Corticotropin-releasing hormone deficiency increases allergen-induced airway inflammation in a mouse model of asthma. J Allergy Clin Immunol 114: 747-54

Wenzel SE (2006) Asthma: defining of the persistent adult phenotypes. Lancet 368: 80413

Williams JT, Begleiter H, Porjesz B, Edenberg HJ, Foroud T, Reich T, Goate A, Van Eerdewegh P, Almasy L, Blangero J (1999) Joint multipoint linkage analysis of multivariate qualitative and quantitative traits. II. Alcoholism and event-related potentials. Am J Hum Genet 65: 1148-60

Xu J, Meyers DA, Ober C, Blumenthal MN, Mellen B, Barnes KC, King RA, Lester LA, Howard TD, Solway J, Langefeld CD, Beaty TH, Rich SS, Bleecker ER, Cox NJ (2001) Genomewide screen and identification of gene-gene interactions for asthma-susceptibility loci in three U.S. populations: collaborative study on the genetics of asthma. Am J Hum Genet 68: 1437-46 


\section{Legend to figure}

Figure 1.

Box-plots of martingale residuals presented for the five values of the asthma score. The black dots indicate the medians.

Figure 2.

Multipoint results of the genome-wide univariate linkage screen for time to asthma onset and asthma score, and of bivariate screen conducted for these two phenotypes in 110 EGEA families with at least two asthmatic sibs. $\log _{10} p$-values are shown on the vertical axis and map distances (in $\mathrm{cM}$ ) on the horizontal axis.

Figure 3.

Multipoint results of univariate linkage analysis for time to asthma onset and asthma score, and of bivariate analysis conducted for these two phenotypes in EGEA families on chromosome 5. $\log _{10} \mathrm{p}$-values are shown on the vertical axis and map distances (in $\mathrm{cM}$ ) on the horizontal axis. 
Table 1. Phenotypic characteristics of 288 genotyped (asthmatics and non-asthmatics) siblings in EGEA families with at least two asthmatic sibs

\begin{tabular}{|c|c|c|}
\hline \multicolumn{3}{|l|}{ All siblings } \\
\hline Asthma, n (\%) & 237 & $(82.3)$ \\
\hline \multicolumn{3}{|l|}{ Asthma score, n (\%) } \\
\hline 0 & 49 & 18.6 \\
\hline 1 & 100 & 38.0 \\
\hline 2 & 51 & 19.4 \\
\hline 3 & 31 & 11.8 \\
\hline 4 & 32 & 12.2 \\
\hline \multicolumn{3}{|l|}{ Asthmatics } \\
\hline Sex, n (\%male) & 141 & $(59.5)$ \\
\hline Age at examination (years), median ( $25-75 \%$ quartiles) & 12.0 & $(10-18)$ \\
\hline Age at asthma onset (years), median (25-75\% quartiles) & 4.0 & $(2-8)$ \\
\hline Duration of asthma disease (years), median ( $25-75 \%$ quartiles) & 8.0 & $(5-11)$ \\
\hline
\end{tabular}

Non-asthmatics

$\begin{array}{lcc}\text { Sex, } \mathrm{n}(\% \mathrm{male}) & 26 & (53.0) \\ \text { Age at examination (years), median }(25-75 \% \text { quartiles }) & 12.0\end{array}$


Table 2. Results of univariate and bivariate multipoint linkage analysis for time to asthma onset and asthma score in French EGEA families.

\begin{tabular}{|c|c|c|c|c|c|c|c|}
\hline \multirow[b]{2}{*}{ Markers } & \multirow[b]{2}{*}{ position * } & \multicolumn{2}{|c|}{ ime to asthma onset } & \multicolumn{2}{|c|}{ Asthma score } & \multicolumn{2}{|c|}{ Bivariate analysis } \\
\hline & & LOD & $\mathbf{p}$ & LOD & $\mathbf{p}$ & $\mathbf{T}^{\dagger}$ & $\mathbf{p}$ \\
\hline $\mathrm{D} 1 \mathrm{~S} 255$ & 65.5 & 1.13 & 0.01 & 0.00 & n.s. & 0.98 & n.s. \\
\hline D1S2797 & 75.7 & 1.70 & 0.003 & 0.10 & n.s. & 5.89 & 0.02 \\
\hline D1S2890 & 85.7 & 0.63 & 0.04 & 0.00 & n.s. & 4.59 & 0.04 \\
\hline D5S647 & 74.1 & 0.55 & 0.06 & 0.02 & n.s. & 7.95 & 0.007 \\
\hline D5S424 & 82.0 & 1.87 & 0.002 & 0.49 & 0.07 & 16.85 & 0.00007 \\
\hline D5S641 & 92.4 & 0.55 & 0.06 & 0.59 & 0.05 & 2.51 & 0.12 \\
\hline D5S428 & 95.4 & 0.35 & n.s. & 1.22 & 0.009 & 3.66 & 0.07 \\
\hline D14S70 & 40.1 & 1.21 & 0.009 & 1.20 & 0.009 & 8.30 & 0.006 \\
\hline D14S288 & 47.5 & 0.99 & 0.02 & 0.75 & 0.03 & 5.61 & 0.02 \\
\hline D14S276 & 56.4 & 0.71 & 0.03 & 0.62 & 0.05 & 5.13 & 0.03 \\
\hline D18S464 & 31.2 & 0.02 & n.s. & 2.06 & 0.001 & 1.40 & n.s. \\
\hline D18S53 & 41.2 & 0.02 & n.s. & 2.40 & 0.0004 & 0.87 & n.s. \\
\hline D18S478 & 52.9 & 0.01 & n.s. & 1.37 & 0.006 & 0.11 & n.s. \\
\hline
\end{tabular}

${ }^{*} \mathrm{cM}$ from pter position of linkage peak based on Marshfield map

$\dagger^{\dagger}$ : linkage test statistic constructed by summing the resulting univariate test statistics (MLB likelihood-ratio statistics) for the two principal components (see text for detailed information)

n.s.: non-significant $\mathrm{p}$-value 